\title{
Exploration and Application of Teaching Reform In The Course of Electromagnetic Field and Electromagnetic Wave
}

\author{
Yong SONG ${ }^{a}$ and Hai-Yi ZHANG ${ }^{b^{*}}$
}

College of Electrical and Information Engineering, Beihua University, Jilin, China

a149527387@qq.com, ${ }^{\mathrm{b}} 44167501 @ q q . c o m$

${ }^{*}$ Corresponding author: Hai-Yi Zhang

Keywords: Presentation; Research teaching ;Matlab

\begin{abstract}
Based on the illumination of the characteristics of Electromagnetic Field and Electromagnetic wave, the reform must be performed. New reforms for the content and teaching methods of the electromagnetic field are brought forward and the experience is summarized in this paper. According to the advanced teaching philosophy and following the laws of the teaching, the teaching and research level of teachers and the overall quality of students have been improved.
\end{abstract}

\section{Introduction}

Electromagnetic field and electromagnetic wave is an important professional basic course for undergraduate students majoring in information. This course is the basis of microwave technology, mobile communication technology, optical fiber communication, RF circuit design, etc. Learning this course requires students to have a good mathematical and physical basis(1).Because the curriculum theory is hard, and many obscure concept of calculation, it is difficult to learn for students. In order to improve the teaching effect of the course and make it better, a series of teaching reform measures have been put forward and achieved certain results. This article will discuss from two aspects of theoretical teaching and experimental teaching.

\section{Reform in teaching methods}

\subsection{The application of Presentation teaching method}

Presentation is a kind of teaching practice, which is stated and explained to the whole class by students during the process of teaching, in the form of individual or group. Presentation is a teaching method that is widely used in classroom teaching in Europe, America and other countries (2).

We use small groups in a limited time, through the PPT, animation, programming, simulation and other forms of teaching materials in a particular section or a special subject to display.

Teachers according to the display of the content of the depth, understanding, expression, as well as whether there is a creative way to give a score, which included in the usual results.

For example, the explanation of Maxwell's electromagnetic equation. The equations are as follows (3).

$$
\begin{aligned}
& \nabla \times H=J+\frac{\partial D}{\partial t} \\
& \nabla \times E=-\frac{\partial B}{\partial t} \\
& \nabla \bullet B=0
\end{aligned}
$$


(1.1) is the modified Ampere's law, Why do you need to fix it? The equation (1.3) shows that there is no free magnetic charge in the space, is it correct?

(1.1) and (1.2) shows the time-varying electric field and time-varying magnetic field can stimulate each other, time-varying electromagnetic field which existence independent, formation of electromagnetic waves in space, and the speed of electromagnetic wave equal to light is(4). How does this conclusion come out? Later whether the experiment confirmed? Students thinking about the above problems Give their own opinion in the Presentation class, not only can deepen the understanding of this part of the content, but also provide help for the follow-up study about electromagnetic wave.

\subsection{The introduction of research teaching methods}

With the traditional "teaching" and "learning" to accept, the research teaching process refers to the combination of scientific research and teaching, research ideas, methods and processes to transform the traditional teaching mode, the purpose is to cultivate students' Cultivation of consciousness, master the research methods, to improve the sense of innovation and independent thinking ability(5).The specific implementation steps of the research teaching are as follows Based on the theoretical knowledge learned in the classroom, the students refer to the literature material, choose the research topic, and draw the conclusion through the Matlab software simulation, and write the report.According to the reasoning calculation is correct, the experimental design is perfect, the simulation results are reasonable and other aspects to give a score, which included in the usual results.

\section{Adjustment and revision of teaching content}

\subsection{The adjustment and revision of teaching syllabus}

On the premise of the compound training program, in order to cooperate with the teaching reform measures, the course of "electromagnetic field and electromagnetic wave" has been adjusted in the content system structure. Revised syllabus, curriculum time from the original 48 hours to 40 hours to increase the experiment 8 hours The usual results increased from the original 10 points to 20 points, from the simple according to attendance and homework assignments given by the combination of Presentation teaching and research methods and the combination of a given score.

\subsection{Revision of teaching content}

Can be seen from the table 1, the teaching content and course arrangement is adjusted before large changes, compression theory hours, increases the content of teaching hours, so that students can master the basic theory and application to lay the foundation, and try to avoid the complicated derivation, pay attention to the combination of theory and practice, the students are easy to accept, and lay a solid foundation for the follow-up professional courses. 
Table1.The revision of the teaching content

\begin{tabular}{|l|l|}
\hline $\begin{array}{l}\text { Adjust the teaching content and course } \\
\text { arrangement (48 hours) }\end{array}$ & $\begin{array}{l}\text { After the adjustment of teaching content and } \\
\text { course arrangement (40 hours) }\end{array}$ \\
\hline Part I: vector analysis (4 hours) & Part I: vector analysis (2 hours) \\
\hline $\begin{array}{l}\text { The second part: the basic law of } \\
\text { electromagnetic field (12 hours) }\end{array}$ & The second part: electrostatic field (6 hours) \\
\hline $\begin{array}{l}\text { The third part: static electromagnetic field (8 } \\
\text { hours) }\end{array}$ & Third part: constant electric field (4 hours) \\
\hline $\begin{array}{l}\text { The fourth part: the boundary value problem } \\
\text { of the static field (4 hours) }\end{array}$ & Fourth part: constant magnetic field (4 hours) \\
\hline $\begin{array}{l}\text { The fifth part: time varying electromagnetic } \\
\text { field (10 hours) }\end{array}$ & $\begin{array}{l}\text { The fifth part: time varying electromagnetic field } \\
\text { (6 hours) }\end{array}$ \\
\hline $\begin{array}{l}\text { Sixth part: plane electromagnetic wave (10 } \\
\text { hours) }\end{array}$ & $\begin{array}{l}\text { Sixth part: plane electromagnetic wave (10 } \\
\text { hours) }\end{array}$ \\
\hline & Presentation: 4hours \\
\cline { 2 - 3 } & research method: 4hours \\
\hline
\end{tabular}

\section{Selection of teaching materials}

Under the background of economic integration and globalization, the higher education must face the world, and cultivate the compound talents who are proficient in the professional knowledge and have a good command of foreign language. 。 It should beadapt to the trend of internationalization of higher education, and actively absorb the latest achievements in the world of science and technology, pay attention to foreign textbook content absorption and reference, the proper use of foreign language teaching. Bill Hayt and John Buck's Engineering Electromagnetic is a classic text that has been updated for electromagnetic education today. This widely-respected book stresses fundamental concepts and problem solving, and discusses the material in an understandable and readable way. Choose this book as auxiliary materials, gives the main sections of professional English words and terms in the lecture, let students improve English education level and comprehensive quality at the same time to learn the theory of knowledge, really do.

\section{Construction of experimental teaching}

Due to the experimental equipment of electromagnetic field and electromagnetic wave is usually more expensive, and higher requirements for the laboratory environment, so the experiment can be carried out through the simulation software, which can do the basis of the experiment and innovative experimental design of (6). Currently more commonly used simulation software is matlab。

MathWorks company produced the MATLAB software is a powerful mathematical software, it can be used for the development of algorithms, analysis of data and numerical values, etc. Matlab can provide different kinds of toolbox, various types of functions and open programming environment, through it we can get the visual image of the two dimensional and three-dimensional simulation graphics. The use of Matlab can visually simulate and demonstrate all kinds of electromagnetic phenomena, enhance visibility, and enrich the content of teaching (7).For example, the use of finite difference method in the experimental teaching. In many practical cases, we often do not know the distribution of the charge, and only know the boundary of the potential. For example, the conductor in the electrostatic field, the boundary is the equipotential surface charge distribution on the surface, 
but often not the same, and difficult to get. If we want to find the electric field near the conductor, through the preparation and operation of the program, you can get an intuitive image.

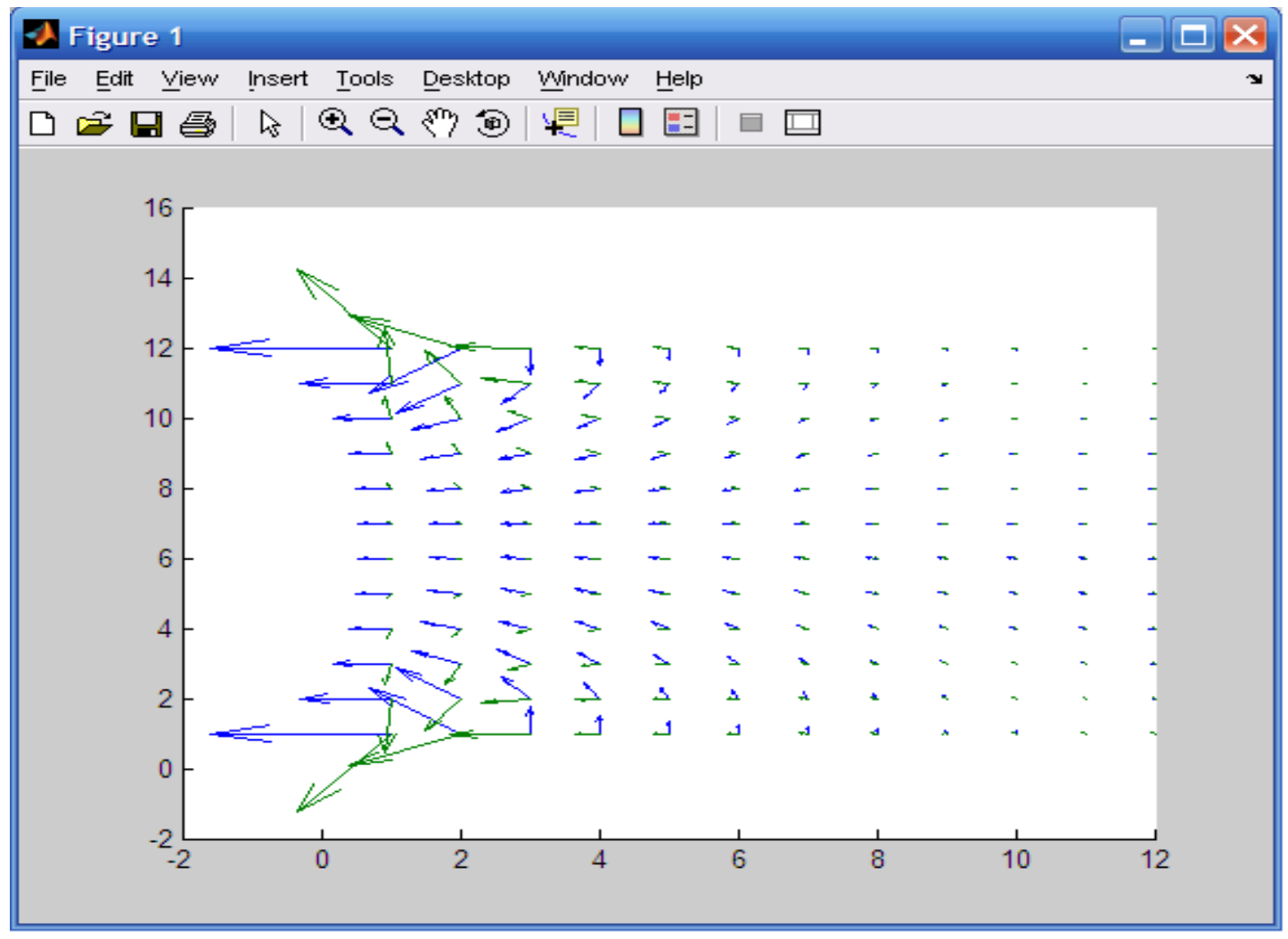

Fig1. Electric field map and power line distribution

\section{Conclusion}

Electromagnetic field and electromagnetic wave as the core course of information, how to organize the teaching content is very important. At the same time, qualitative analysis and quantitative calculation of electromagnetic phenomenon is one of the professional skills of students. Therefore, this course is not only to prepare the necessary foundation for further study, but also more profound is related to the basic quality of the training of students. Teaching practice shows that the teaching reform of this course is effective, and the students' interest in the study of "electromagnetic field and electromagnetic wave" is obviously improved.

\section{References}

[1] Wang Shibin, Zhang Lian, Wan Peilin . The practice of teaching content reform in the field of electromagnetic field [J].Chinese Journal of electrical and electronic education, 2006, 28 (5):8-11

[2] FAN Da- zhao, LEI Rong.Application Investigation of Presentation in Photogrammetry Teaching [J]Geomatics \& Spatial Information Technology,2013,36(6):1-2.

[3] Xie chufang, Rao Kejin. Electromagnetic field and electromagnetic wave (Fourth Edition) [M]. Beijing: Higher Education Press, 2015

[4] Wang Jiali, Zhu manzuo, Lu Hongmin. Electromagnetic field and electromagnetic wave (Third Edition) [M]. Shaanxi: Xi'an Electronic and Science University press. 
[5] Li Zhenhua, Yu Jie, Li Zhenxing. Application of research methods in Engineering Electromagnetic Field Teaching [J]. New curriculum research, 2016( 06):1-19.

[6] Huo Jiayu, Gao Bo. Electromagnetic field and electromagnetic wave experimental teaching research and exploration of [J].Laboratory Science, 2016,19 (2).

[7] Shao Xiaotao, Guo Yong, Li Yimei. "The course of electromagnetic field and wave M at l ab [J]. teaching electrical and electronic teaching journal, 2010, 32 (5):11-13. 